\title{
The chemokine receptor CXCR3 is expressed on malignant $B$ cells and mediates chemotaxis
}

\author{
Livio Trentin, ${ }^{1}$ Carlo Agostini, ${ }^{1}$ Monica Facco, ${ }^{1}$ Francesco Piazza, ${ }^{1}$ Alessandra Perin, ${ }^{1}$ \\ Marta Siviero, ${ }^{1}$ Carmela Gurrieri, ${ }^{1}$ Silvia Galvan, ${ }^{1}$ Fausto Adami, ${ }^{1}$ Renato Zambello, ${ }^{2}$ \\ and Gianpietro Semenzato ${ }^{1}$
}

${ }^{1}$ Padua University School of Medicine, Department of Clinical and Experimental Medicine, Clinical Immunology Branch, 35128 Padova, Italy

${ }^{2}$ Division of Hematology, Vicenza Hospital, 36100 Vicenza, Italy

Address correspondence to: Gianpietro Semenzato, Università di Padova, Dipartimento di Medicina Clinica e Sperimentale, Immunologia Clinica, Via Giustiniani 2, 35128 Padova, Italy. Phone: 39-049-821-2298;

Fax: 39-049-875-4179; E-mail: giansem@ux1.unipd.it.

Received for publication May 13, 1999, and accepted May 18, 1999.

\begin{abstract}
B- and T-cell recirculation is crucial for the function of the immune system, with the control of cell migration being mainly mediated by several chemokines and their receptors. In this study, we investigated the expression and function of CXCR3 on normal and malignant B cells from 65 patients with chronic lymphoproliferative disorders (CLDs). Although CXCR3 is lacking on $\mathrm{CD}^{+}$and $\mathrm{CD}^{-} \mathrm{B}$ cells from healthy subjects, it is expressed on leukemic B lymphocytes from all (31/31) patients with chronic lymphocytic leukemia (CLL). The presence of CXCR3 was heterogeneous in other B-cell disorders, being expressed in 2 of 7 patients with mantle cell lymphoma (MCL), 4 of 12 patients with hairy cell leukemia (HCL), and 11 of 15 patients with other subtypes of non-Hodgkin's lymphomas (NHLs). Chemotaxis assay shows that normal B cells from healthy subjects do not migrate in response to IFNinducible protein 10 (IP-10) and IFN- $\gamma$-induced monokine (Mig). In contrast, a definite migration in response to IP-10 and Mig has been observed in all malignant B cells from patients with CLL, but not in patients with HCL or MCL (1/7 cases tested). Neoplastic B cells from other NHLs showed a heterogenous pattern. The migration elicited by IP-10 and Mig was inhibited by blocking CXCR3. No effect of IP-10 and Mig chemokines was observed on the cytosolic calcium concentration in malignant $B$ cells. The data reported here demonstrate that CXCR3 is expressed on malignant B cells from CLDs, particularly in patients with CLL, and represents a fully functional receptor involved in chemotaxis of malignant B lymphocytes.
\end{abstract}

J. Clin. Invest. 104:115-121 (1999).

\section{Introduction}

The superfamily of chemokines consists of an array of chemoattractant proteins that has been divided into 4 branches (C, CC, CXC, and CXXC) on the basis of the relative position of the cysteine residues in the mature protein (1-6). Structural variations of chemokines have been demonstrated to be associated with differences in their ability to regulate the trafficking of immune cells during hematopoiesis and inflammatory responses (1, 2, 7). Chemokines exert their attractant properties after binding to distinct membrane receptors. Because a single chemokine receptor binds several chemokines, it is often difficult to evaluate the activity of these structures in lymphocyte homing. For instance, IFN-inducible protein 10 (IP-10) and IFN- $\gamma$-induced monokine (Mig) 2 CXC chemokines that are induced by IFN- $\gamma(1,4)$, bind the CXCR3 receptor and have been shown to be specifically chemotactic for activated lymphocytes (8).

The recently cloned CXCR3 receptor CDNA (8) has been reported to be expressed on activated $\mathrm{T}$ lymphocytes after in vitro stimulation, but it is usually lacking in, or present in only a small fraction of, resting $\mathrm{T}$ lym- phocytes, B cells, monocytes, and granulocytes (9-14). It has been initially observed to mediate calcium changes and chemotaxis in response to IP-10 and Mig, but not to other chemokines $(1,4)$. Recently, IFNinducible T-cell alpha chemoattractant (I-TAC) has also been observed to bind CXCR3 (13).

The mechanisms controlling malignant B-cell trafficking in the macro- and microenvironments are poorly understood. It is not clear why some disorders are preferentially confined to a limited number of organs, e.g., hairy cell leukemia (HCL), and why others, e.g., Bcell chronic lymphocytic leukemia (CLL), present with a wide diffusion to peripheral blood and other structures at the onset of the disease. In this study, we investigated the expression and chemotactic function of the CXCR3 receptor on normal B lymphocytes from healthy subjects and on malignant $B$ cells from patients with different types of B-cell chronic lymphoproliferative disorders (CLDs), including $\mathrm{CD}^{+} \mathrm{B}$-cell disorders, e.g., CLL and mantle cell lymphoma (MCL), and CD5 CLD, e.g., HCL and several subtypes of non-Hodgkin's lymphomas (NHLs). 

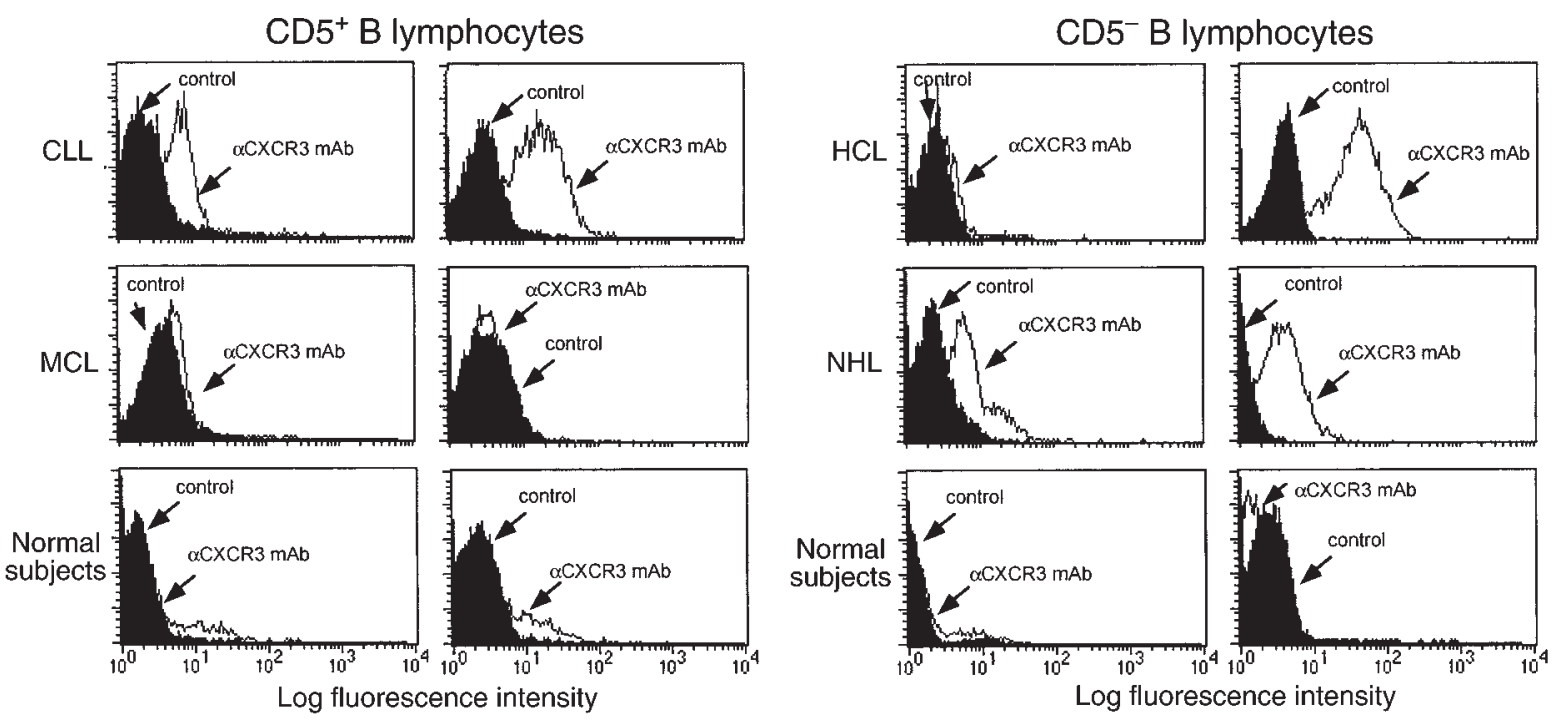

Figure 1

Flow cytometry analysis of the expression of CXCR3 receptor on $C D 5^{+}$and $C D 5^{-} B$ cells from healthy subjects and on malignant $B$ lymphocytes recovered from 2 representative patients with different types of CLDs. The figure is consistent with the data reported in Table 1, as CXCR3 was commonly expressed in almost all patients with CLL and in the large majority of patients with NHL.

\section{Methods}

Patient samples. Sixty-five patients with different B-cell malignancies had been studied at the time of diagnosis. Thirty-one patients ( 16 men and 15 women, ages 48-78 years) with the diagnosis of B-CLL (15) were graded according to the Rai staging system (16) as follows: stage 0 ( 3 cases), stage I (12 cases), stage II (10 cases), stage III ( 4 cases), and stage IV ( 2 cases); the total lymphocyte count ranged from 16,000 to $98,000 / \mathrm{mm}^{3}$.

Seven patients ( 6 men and 1 woman, ages $54-72$ years) with the diagnosis of MCL (15) and with malignant $B$ cells in the peripheral blood were studied.

Twelve patients with HCL ( 7 men and 5 women, ages 44-68 years) were studied. The diagnosis was established on the basis of clinical, morphological, cytochemical, histological, and immunological features (17). Fifteen patients ( 7 men and 8 women) with different histological entities of NHL (4 marginal zone, 8 lymphocytic, and 3 lymphoplasmacytic) in the leukemic phase were studied.

Preparation of cell suspensions. PBMCs from patients with B-CLD were obtained from freshly heparinized blood samples by centrifugation on Ficoll-Hypaque $(\mathrm{F} / \mathrm{H})$ gradient (18). Normal B lymphocytes were obtained from 2 spleen specimens and from 6 tonsils after mechanic disruption (19). Mononuclear cells, recovered after centrifugation on $\mathrm{F} / \mathrm{H}$ gradient, were washed 3 times with PBS and resuspended in endotoxin-free RPMI-1640 medium (Sigma Chemical Co., St. Louis, Missouri, USA) supplemented with $20 \mathrm{mM}$ HEPES and L-glutamine, $100 \mathrm{U} / \mathrm{mL}$ penicillin, 100 $\mu \mathrm{g} / \mathrm{mL}$ streptomycin, and 10\% FCS (ICN Flow, Costa Mesa, California, USA) (19)

Cell samples with a percentage of monocytes and $T$ and natural killer (NK) cells greater than 5\% were further enriched in B lymphocytes by rosetting with sheep red blood cells treated with neuroaminidase (Sigma Chemical Co.) and by removing residual $\mathrm{CD}^{+}, \mathrm{CD} 16^{+}$, $\mathrm{CD}^{2} 6^{+}$, and $\mathrm{CD} 14^{+}$cells using magnetic separation columns (Miltenyi Biotec, Bergisch Gladbach, Germany), as described previously (20). After the multistep negative selection procedure, more than $98 \%$ of the resulting cell population was $\mathrm{CD}_{19}{ }^{+}$. The purification of $\mathrm{CD}^{+} \mathrm{B}$ cells was performed by a positive selection using anti-CD5 mAb's.

$m A b$ 's and cytokines. CXCR3 receptor analysis was performed using 1C6 mAb (kindly provided by S. Qin, LeukoSite, Cambridge, Massachusetts, USA) (9). IP-10 and Mig chemokines were purchased from R\&D Systems Inc. (Minneapolis, Minnesota, USA).

For FACS analysis, $10^{-4}$ cells were acquired and the analysis was determined by overlaying the histograms of the samples stained with the different reagents. Cells were scored using a FACScan analyzer (Becton Dickinson Immunocytometry Systems, San Jose, California, USA), and data were processed using the CellQuest or Lysys software programs (Becton Dickinson Immunocytometry Systems). Mean log fluorescence intensity (MFI) values were obtained by subtracting the MFI of the isotype control from the MFI of the positively stained sample. Furthermore, to evaluate whether the differences between the peaks of cells were statistically significant with respect to control, the Kolmogorov-Smirnov test for analysis of histograms was used, according to the CellQuest software user's guide.

Migration assay. Cell migration was measured in a 48well modified Boyden chamber. The rhIP-10 and rhMig chemokines were diluted in RPMI-1640 medium at different concentrations ( 20 and $200 \mathrm{ng} / \mathrm{mL}$ for IP-10; 100 and $1,000 \mathrm{ng} / \mathrm{mL}$ for Mig) and were used to 
evaluate the chemotactic properties of B lymphocytes from healthy donors and patients. The $\mathrm{CXCR}^{-}$and $\mathrm{CXCR}^{+}$cell lines (300-19; kindly provided by B. Moser, Theodor-Kocher Institute, University of Bern, Bern, Switzerland) were used as negative and positive controls, respectively. Poly-vinylpyrrolidone-free polycarbonate membranes coated with fibronectin were used (3- $\mu \mathrm{m}$ pores for CLD; $5-\mu \mathrm{m}$ pores for cell lines). A total of $30 \mu \mathrm{L}$ of chemokines or control medium was added to the bottom wells, and $50 \mu \mathrm{L}$ of $5.0 \times 10^{6}$ cells/mL B cells or CXCR3-/CXCR3 ${ }^{+}$cells resuspended in RPMI-1640 was added to the top wells. The chamber was incubated at $37^{\circ} \mathrm{C}$ with $5 \% \mathrm{CO}_{2}$ for 2 hours. The membranes were then removed, washed with $\mathrm{PBS}$ on the upper side, and fixed and stained with Diff-Quick (Dade AG, Düdingen, Switzerland). Cells were counted at $\times 800$ magnification in 3 fields per well. All assays were performed in triplicate. In blocking experiments, cell suspensions were preincubated before chemotaxis assay for 30 minutes at $4^{\circ} \mathrm{C}$ with anti-human CXCR3 mAb at the concentration of $20 \mu \mathrm{g} / \mathrm{mL}$.

Cytosolic calcium. Changes in the intracellular calcium concentration $\left(\left[\mathrm{Ca}^{2+}\right]_{i}\right)$ were measured in 10 patients with CLL with the fluorescent indicator fura-2/AM, as described previously (22). Briefly, $20 \times 10^{6}$ cells were incubated with $2 \mu \mathrm{M}$ fura- $2 / \mathrm{AM}$ at $37^{\circ} \mathrm{C}$ for $40 \mathrm{~min}$ utes. After the loading procedure, aliquots of the cells $\left(2 \times 10^{6}\right)$ were rapidly washed and resuspended in a magnetically stirred thermostatted cuvette. Excitation and emission wavelengths were 340 and $500 \mathrm{~nm}$, respectively; the excitation slit width was $5 \mathrm{~nm}$, and the emission slit was $10 \mathrm{~nm}$. The inhibitor of organic ion transport sulfinpyrazone was added in some experiments during $\left[\mathrm{Ca}^{2+}\right]_{\mathrm{i}}$ measurements at a concentration
Table 1

Flow cytometry analysis of CXCR3 in B-cell CLDs and normal subjects

\begin{tabular}{lcccccc}
\hline & \multicolumn{3}{c}{ CD5 ${ }^{+}$B lymphocytes } & \multicolumn{3}{c}{ CD5- B lymphocytes } \\
& $\begin{array}{c}\text { Healthy } \\
\text { subjects }\end{array}$ & $\mathrm{CLL}$ & $\mathrm{MCL}$ & $\begin{array}{c}\text { Healthy } \\
\text { subjects }\end{array}$ & $\mathrm{HCL}$ & $\mathrm{NHL}$ \\
MFIA $^{\mathrm{A}}$ & $26 \pm 3$ & $172 \pm 17$ & $120 \pm 50$ & $35 \pm 6$ & $79 \pm 32$ & $151 \pm 38$ \\
$P$ & & $P<0.001$ & $\mathrm{NS}$ & & $\mathrm{NS}$ & $P<0.05$ \\
No. positive & $0 / 6$ & $31 / 31$ & $2 / 7$ & $0 / 6$ & $4 / 12$ & $11 / 15$
\end{tabular}

${ }^{A}$ Data are reported as mean \pm SE of the MFI values for each group of subjects after subtracting the MFI of isotype control mAb from the MFI of positively stained samples. Comparisons between patients' values and control subjects were made using the Student's $t$ test. $P<0.05$ was considered as significant. NS, not significant.

of $250 \mu \mathrm{M}$ to prevent fura- 2 release into the medium (23). Control experiments without sulfinpyrazone gave essentially the same results, except for a slowly increasing baseline due to fura-2 leakage (23).

Statistical analysis. Data are expressed as mean \pm SEM, and comparisons between values were made using the Student's $t$ test. $P<0.05$ was considered as significant.

\section{Results}

Expression of CXCR3 chemokine receptor on normal and malignant $B$ cells. The CXCR3 chemokine receptor was analyzed on normal B lymphocytes obtained from healthy donors and on tumor B cells recovered from patients with different B-cell malignancies (Table 1). Among different groups of disorders, high levels of CXCR3 expression were observed on B cells from CLL $(172 \pm 17 \mathrm{MFI})$ and NHL $(151 \pm 38 \mathrm{MFI})$ compared with normal $\mathrm{CD}^{+}$and $\mathrm{CD}^{-} \mathrm{B}$ lymphocytes $(26 \pm 3$ and $35 \pm$ 17 MFI, respectively), with $P<0.001$ and $<0.05$, respectively. By contrast, only a few patients with HCL (4/12)

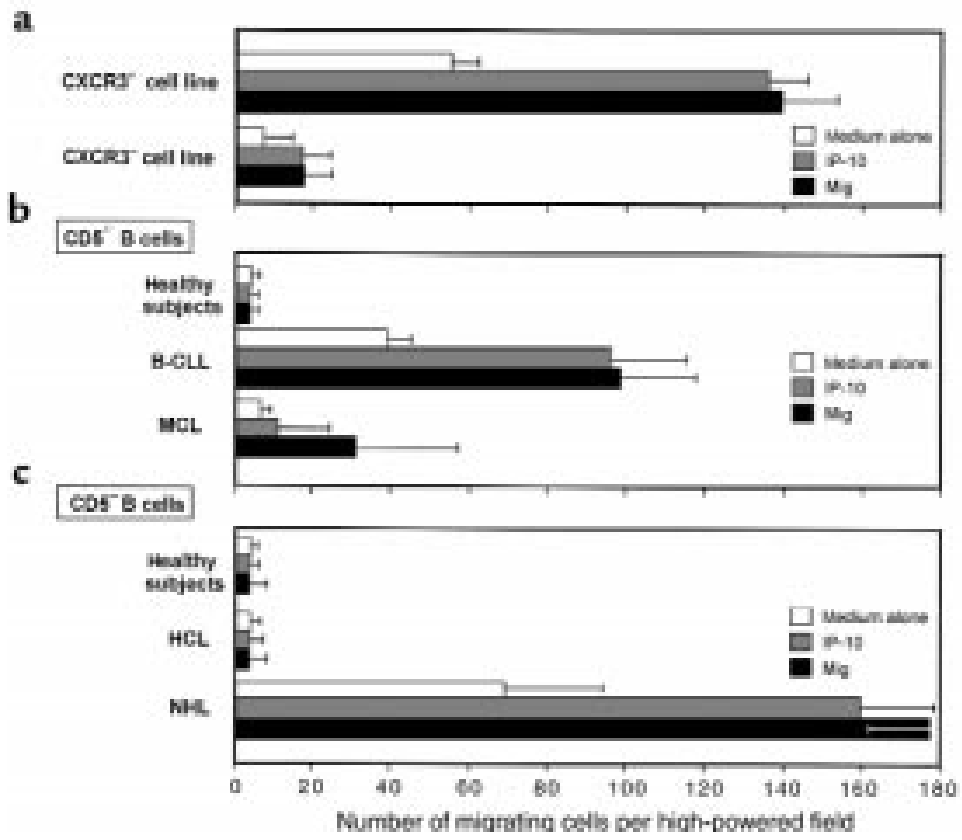

\begin{abstract}
Figure 2
Chemotactic activity of $\mathrm{CXCR}^{+}$and $\mathrm{CXCR} 3^{-}$cell lines and normal and malignant $\mathrm{CD}^{+}$and $\mathrm{CD} 5^{-}$ $B$ lymphocytes. The data reported were obtained in medium alone, in the presence of $200 \mathrm{ng} / \mathrm{mL}$ of IP-10, and in the presence of $1,000 \mathrm{ng} / \mathrm{mL}$ of Mig. The data illustrated indicate that both IP10 and Mig chemokines induce chemotaxis on malignant $\mathrm{B}$ cells recovered from patients with CLL and NHL.
\end{abstract}


b
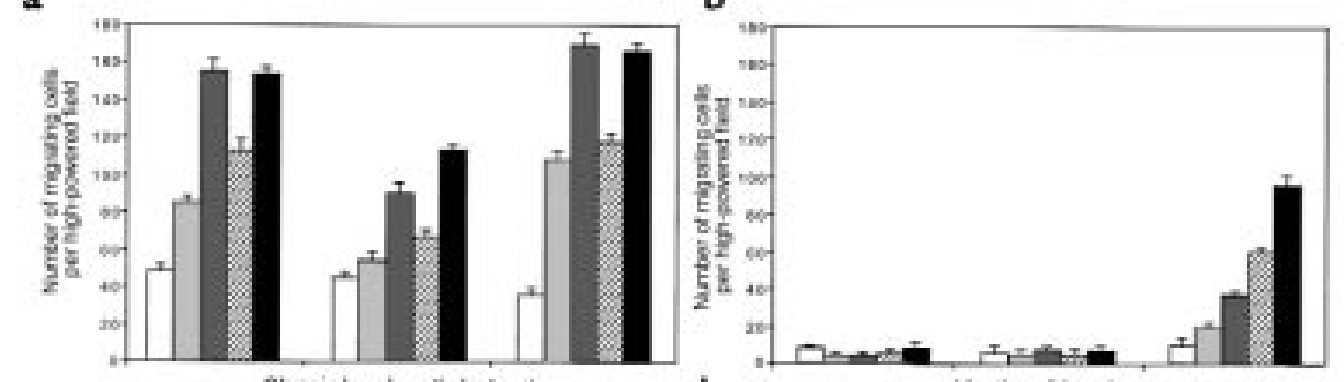

c
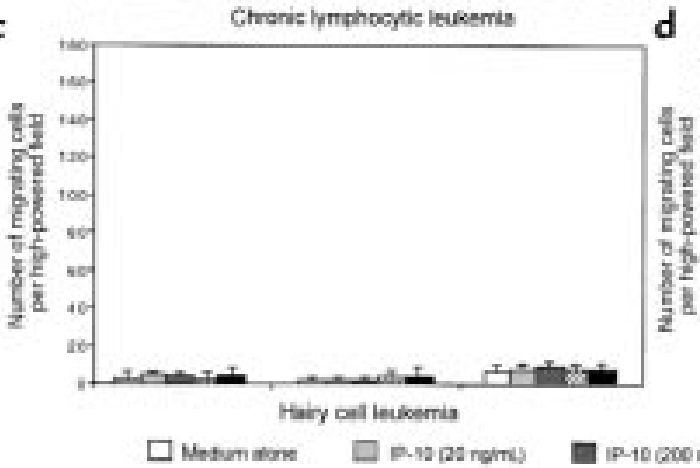

Martle of hmphoms

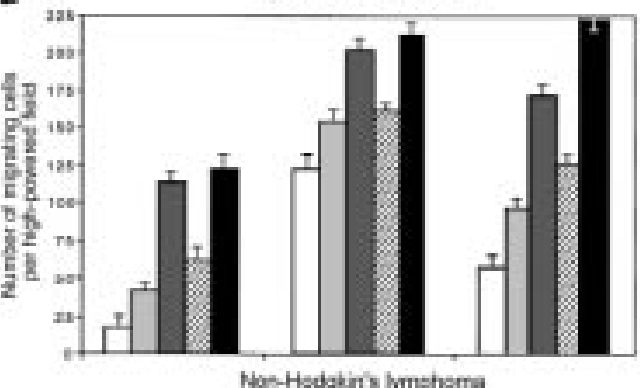

Nos-Hodgkins hmshome

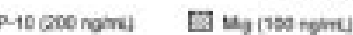

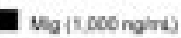

Figure 3

Chemotactic activity of representative patients with $\mathrm{CD}^{+}$and CD5- B-lymphocyte malignancies to different concentrations of IP-10 (20 and $200 \mathrm{ng} / \mathrm{mL}$ ) and Mig (100 and 1,000 ng/mL). The chemotaxis elicited by IP-10 and Mig is related to the concentrations used.

and MCL (2/7) expressed CXCR3. Representative flow cytometry histograms obtained from subjects belonging to different groups are reported in Figure 1.

Cell migration assay. To characterize further the biological properties of the CXCR3 chemokine receptor, normal and malignant $\mathrm{B}$ cells were assessed for their migration properties. Normal $\mathrm{CD}^{+}$and $\mathrm{CD}^{-} \mathrm{B}$ cells from healthy subjects displayed very low or undetectable migration activity (Figure 2, b and c). Among $\mathrm{CD5}^{+} \mathrm{B}$-cell malignancies, CLL leukemic cells from 13 of 13 patients tested exhibited a high migration activity both at resting conditions and after triggering with IP-10 and Mig chemokines, whereas $\mathrm{CD5}^{+}$tumor $\mathrm{B}$ cells from patients with MCL displayed low or undetectable migration. When $\mathrm{CD}^{-}$- malignant $\mathrm{B}$ cells were considered (Figure 2c), hairy cells did not display any migration activity at resting conditions or after in vitro incubation with IP-10 and Mig chemokines. Furthermore, tumor B lymphocytes recovered from subjects with NHL displayed a discrete chemotactic function, with the highest activity being usually observed in marginal zone NHL.

Migration activity displayed by representative cases is shown in Figure 3. The test was performed with freshly isolated B cells in the absence and presence of different concentrations of IP-10 and Mig chemokines. Data reported here demonstrate that migration is mainly induced in CLL and NHL, whereas MCL and HCL tumor $\mathrm{B}$ cells are poorly induced to migrate. In addition, among patients with NHL, the highest activity was demonstrated in 2 subjects with marginal zone Bcell lymphoma.
To verify further the role of CXCR3 in B-cell chemotaxis, malignant $\mathrm{B}$ cells responsive to IP-10- and Miginduced chemotaxis were preincubated with antiCXCR3 mAb. The blocking of the CXCR3 receptor determined a marked inhibition of both IP-10- and Mig-induced chemotaxis (Figure 4).

Cytosolic calcium measurement. We also examined the ability of IP-10 and Mig to stimulate functional responses in malignant B cells from patients with CLD through the evaluation of cytosolic calcium levels. The analysis was performed in 10 patients with CLL, and data related to 3 representative cases are reported in Figure 5. The assay was performed with both IP-10 and Mig at a $1 \mu \mathrm{M}$ concentration. The data reported here demonstrate that no increase in $\left[\mathrm{Ca}^{2+}\right]_{\mathrm{i}}$ was observed after the addition of IP-10 or Mig chemokines to malignant B cells. In contrast, a significant increase was observed after addition of an anti-immunoglobulin antibody.

\section{Discussion}

The data reported here demonstrate that CXCR3 is constitutively expressed on malignant $\mathrm{B}$ cells obtained from patients with B-CLL, whereas its expression on other B-cell disorders is quite heterogeneous. Chemotactic in vitro studies showed that CXCR3 behaves as a functional receptor on CLL cells, as it transduces chemotactic activity after binding to relevant chemokines (IP-10 and Mig).

Data from the literature have demonstrated that CXCR3 is commonly expressed on activated T cells and on a discrete proportion of resting $\mathrm{T}$ and NK cells (9, $11,24)$. As far as normal B cells are concerned, only a 
few peripheral blood B lymphocytes express the CXCR3 receptor (9). Our findings extend these observations to the malignant counterpart of $\mathrm{B}$ cells and clearly indicate that CXCR3 is expressed on circulating $\mathrm{B}$ cells from patients with B-cell malignancies, in particular from patients with CLL. The observation that CXCR3 is expressed on CLL leukemic cells suggests that this receptor might represent a hallmark of this disease. In fact, the expression of CXCR3 in other B-cell malignancies studied in this work is quite heterogeneous, usually absent in HCL, and expressed at variable degrees of intensity in other NHLs. When compared with purified normal B cells, the differences in terms of MFI were statistically significant in CLL and NHL, but not in HCL and MCL.

Lymphocyte trafficking is a critical step of the systemic immunity (1-3). This process includes migration of $\mathrm{T}$ lymphocytes from the bone marrow and thymus to spleen and lymph nodes, as well as the migration of B lymphocytes in the lymph node microenvironment, i.e., from the mantle zones to germinal centers. Considering the promiscuity of chemokines and their receptors, it is still difficult to understand how the cellular trafficking is regulated. Although the functions of some chemokines, e.g., stromal cell-derived factor-1 (SDF-1), are well characterized in terms of their ability to recruit $\mathrm{B}$ cells into the microenvironment of stroma cells (25), the role of IP-10 and Mig in B-cell trafficking is not defined. In addition to their chemotactic activity for T lymphocytes, IP-10 and Mig share other properties, including inhibition of neovascularization, inhibition of progenitor cells, and antitumor effects (4). For these reasons, the expression of CXCR3 may have a dual effect in these B-cell malignancies. Its presence may favor the trafficking of malignant $B$ cells from one site to another site of disease involvement, thus favoring the spreading of the disease to peripheral blood, lymph nodes, bone marrow, and other organs. It could also be suggested that the interaction between CXCR3 and relevant chemokines might affect tumor growth by attracting $\mathrm{T}$ cells with antitumor functions. In this view, a selection of $\mathrm{T}$ cells with a limited $\mathrm{T}$ cell-receptor repertoire has been observed in CLL and HCL $(26,27)$; these findings might be viewed as a possible consequence of an antitumor reaction.

The functional data on the CXCR3 receptor reported in this work deserve 2 considerations. The first comes from the demonstration that malignant $\mathrm{B}$ cells from patients with CLD are equipped with a chemotactic activity, not only in response to IP-10 and Mig chemokines but also in the absence of exogenous chemokine stimuli, indicating that these cells spontaneously migrate in vitro. This effect was clearly detectable in patients with CLL and NHL. This finding may trigger speculation that other chemokines are likely to be involved in B-cell chemotaxis in patients with CLD. A second question deals with the evidence that although the triggering of the B-cell receptor by anti-immunoglobulin antibodies induced increases in the cytosolic calcium concentration, IP-10 and Mig binding to CXCR 3 on malignant B cells did not. This latter observation might be a consequence of the density of CXCR3 expression on malignant B cells or of the state of activation of these cells. In this regard, an increase in cytosolic calcium levels has not been detected on resting human $T$ lymphocytes, although the cells are equipped with surface CXCR3 (28). Calcium flux was observed only after in vitro preactivation of relevant cells (28). Alternatively, our findings could be the result of different in vitro experimental conditions to detect chemotaxis (i.e., migration assay in cells adhering to a substratum) and cytosolic calcium levels (i.e., calcium measurement in cell suspension) in the in vivo setting (29). This interpretation is consistent with recent evidence that calcium flux and chemotaxis are dissociated phenomena. In fact, calcium fluxes have been shown to be neither necessary nor sufficient for chemotaxis in standard assays using a variety of chemotactic factors (28).

The evidence that CLL (a disease with a diffuse spreading) constitutively expresses CXCR3, whereas HCL (a disease usually limited to the spleen and bone
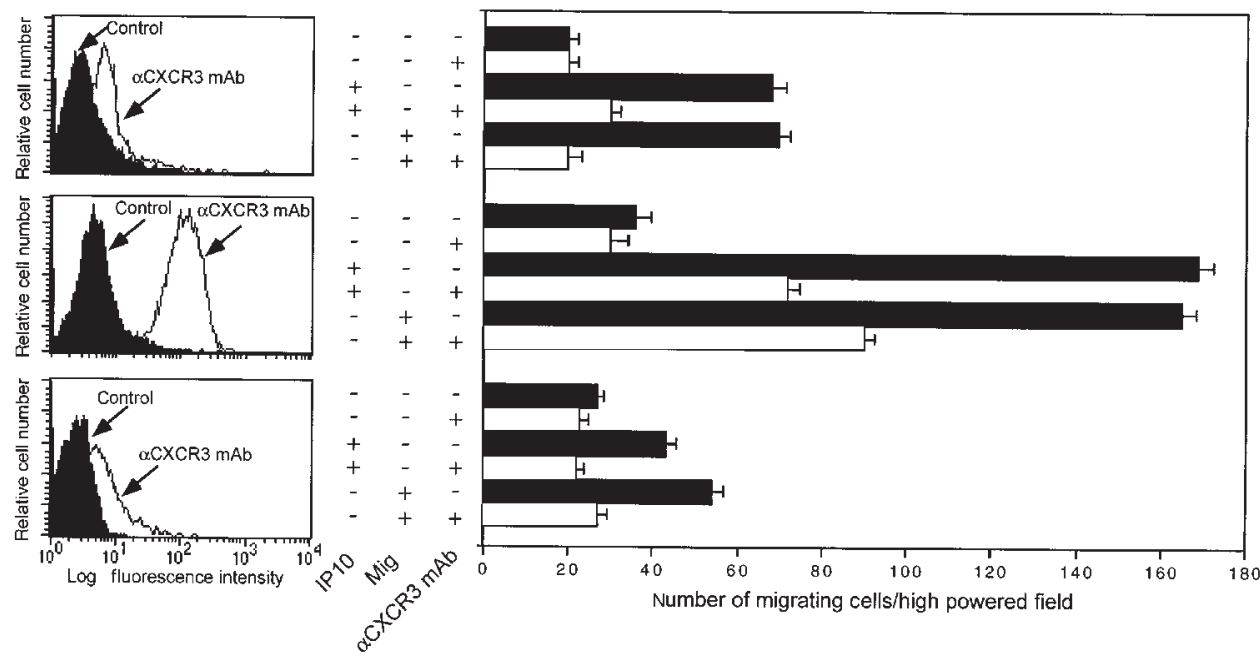

\section{Figure 4}

Role of CXCR3 receptor blocking on IP-10- and Mig-induced chemotaxis in 3 representative patients with CLDs. The preincubation of malignant $B$ cells with anti-CXCR3 mAb inhibited the chemotactic activity elicited by IP-10 and Mig. 

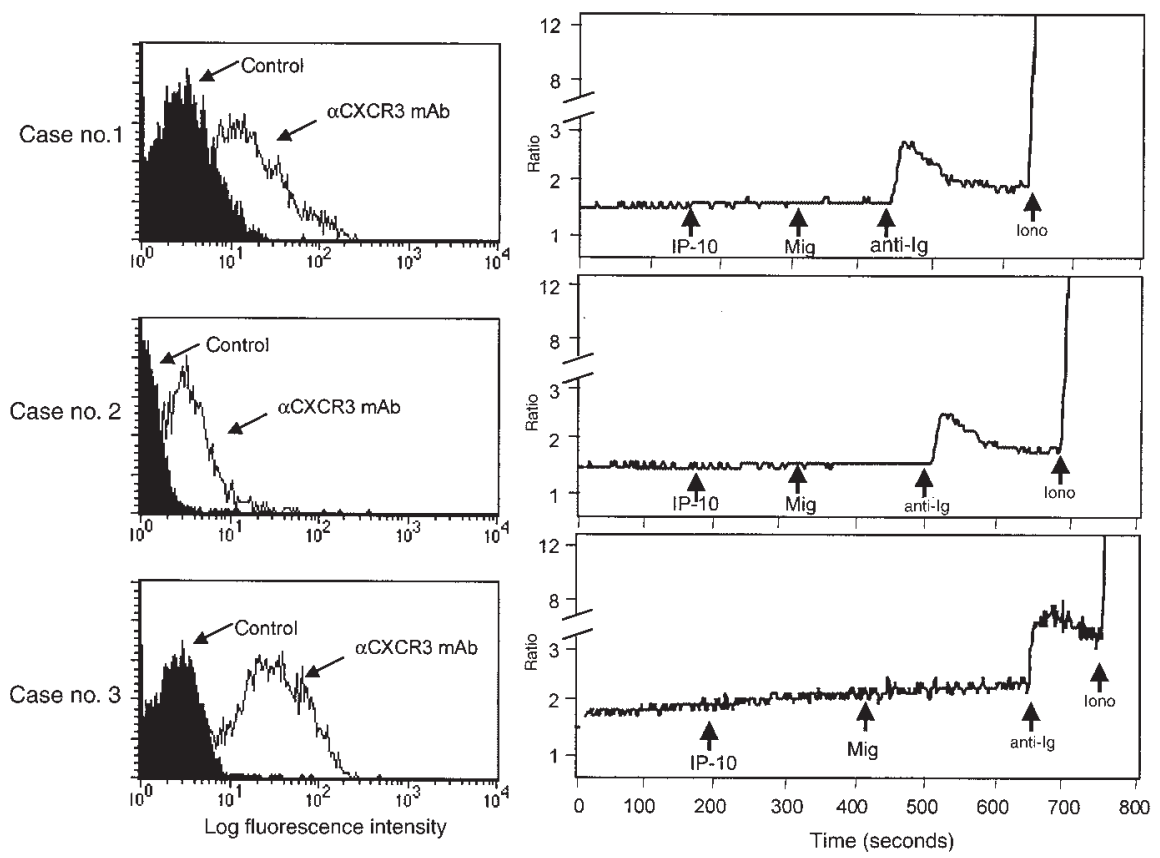

\section{Figure 5}

Effect of IP-10 and Mig on cytosolic calcium concentration in 3 representative patients with CLL. Neither IP-10 nor Mig induced calcium mobilization in patients with leukemic CLL. A discrete calcium increase was observed after cross-linking surface membrane immunoglobulins. When indicated, the concentration of the stimuli was 1 $\mu \mathrm{g} / \mathrm{mL}$. At the end of each experiment, the calcium ionophore ionomycin $(1 \mu \mathrm{M})$ was added to induce a massive calcium increase. The values are expressed as the ratio between the intensity of the fluorescence signals obtained by exciting at 340 and 380 $\mathrm{nm}$. An increase in this ratio reflects an increase in $\left[\mathrm{Ca}^{2+}\right]_{i}$. The marginal increase of case no. 3 was also observed in cells not treated with the stimuli, and presumably reflects a slow release of fura- 2 into the medium. marrow) does not express CXCR3, indicates that this receptor plays a crucial role in the homing of malignant $B$ cells. Although we did not find any correlation between the number of malignant $\mathrm{B}$ cells in the peripheral blood and the intensity of the expression of CXCR3 on these cells, the highest levels of MFI were observed in patients with high numbers of hairy cells in the peripheral blood, compared with patients with only few circulating hairy cells. Furthermore, the evidence that patients with HCL have low or undetectable numbers of monocytes, which represent a relevant source of these chemokines, may further support the inability or the difficulty of hairy cells to spread to blood and lymph nodes. With respect to patients with NHL, our data demonstrate that some of them, e.g., marginal zone B-cell lymphomas with spleen involvement, bear CXCR3 receptor and show a strong migration activity. This finding might be interpreted as a further demonstration that this receptor might correlate with the homing of malignant B cells and, in this particular histotype, with the capability of these cells to migrate to circulation and different lymphoid organs.

The complexity of this trafficking comes from the demonstration that most chemokines bind to 1 or more receptors and that a single receptor can bind several cytokines, usually either CC or CXC chemokines, but not both. In contrast, CXCR3 has been observed to bind, although with low affinity, CCR3 ligands that may affect CXCR3-mediated properties (24). Therefore, the number of receptors on the cell surface, and its affinity and chemokine gradients at the site of malignant involvement, may play a key role in favoring the spread or extension of the neoplastic process. In this context, it may be hypothesized that in the future the clinical use of receptor antagonists, e.g., eotaxin and other chemokines (30), might positively affect the spreading of the disease.

\section{Acknowledgments}

This work was supported by the Italian Association for Cancer Research (AIRC) and by the Ministero dell' Universitá e della Ricerca Scientifica e Technologica (MURST). The authors thank Tullio Pozzan and Cristina Fasolato for calcium flux evaluation and for reviewing the manuscript; Martin Donach for help in the preparation of the manuscript; S. Qin for providing the anti-CXCR3 $\mathrm{mAb}$; and $\mathrm{B}$. Moser for providing the 30019 cell line.

1. Baggiolini, M., Dewald, B., and Moser, B. 1997. Human chemokines: an update. Annu. Rev. Immunol. 15:675-705.

2. Baggiolini, M. 1998. Chemokines and leukocyte traffic. Nature. 392:565-568.

3. Rollins, B. 1997. Chemokines. Blood. 90:909-928.

4. Farber, J.M. 1997. Mig and IP-10: CXC chemokines that target lymphocytes. J. Leukoc. Biol. 61:246-257.

5. Yoshie, O., Imai, T., and Nomiyama, H. 1997. Novel lymphocyte-specific CC chemokines and their receptors. J. Lenkoc. Biol. 62:634-644.

6. Nelson, P.J., and Krensky, A.M. 1998. Chemokines, lymphocytes and viruses: what goes around, comes around. Curr. Opin. Immunol. 10:265-270.

7. Luster, A. 1998. Chemokines: chemotactic cytokines that mediate inflammation. N. Engl. J. Med. 228:436-445.

8. Loetscher, M., et al. 1996. Chemokine receptor specific for IP10 and Mig: structure, function and expression in activated T-lymphocytes. J. Exp. Med. 184:963-969.

9. Qin, S., et al. 1998. The chemokine receptors CXCR3 and CCR5 mark subsets of T cells associated with certain inflammatory reactions. J. Clin. Invest. 101:746-754.

10. Piali, L., et al. 1998. The chemokine receptor CXCR3 mediates rapid and shear-resistant adhesion-induction of effector $\mathrm{T}$ lymphocytes by the chemokines IP10 and Mig. Eur. J. Immunol. 28:961-972.

11. Loetscher, M., Loetscher, P., Brass, N., Meese, E., and Moser, B. 1998. Lymphocyte-specific chemokine receptor CXCR3: regulation, chemokine binding and gene localization. Eur. J. Immunol. 28:3696-3705.

12. Sallusto, F., Lenig, D., MacKay, C.R., and Lanzavecchia, A. 1998. Flexible programs of chemokine receptor expression on human polarized helper 1 and 2 lymphocytes. J. Exp. Med. 187:875-883.

13. Cole, K.E., et al. 1998. Interferon-inducible T cell alpha chemoattractant (I-TAC): a novel non-ELR CXC chemokine with potent activity on activated T cells through selective affinity binding to CXCR3. J. Exp. Med. 187:2009-2021.

14. Kim, C.H., and Broxmeyer, H.E. 1999. Chemokines: signal lamps for trafficking of T and B cells for development and effector function. J. Leukoc. Biol. 65:6-15. 
15. Harris, N.L., et al. 1994. A revised European-American classification of lymphoid neoplasms: a proposal from the international lymphoma study group. Blood. 84:1361-1392.

16. Rai, K.R., et al. 1975. Clinical staging of chronic lymphocytic leukemia. Blood. 46:219-234.

17. Trentin, L., et al. 1992. Expression and functional role of the p75 interleukin 2 receptor chain on leukemic hairy cells. Cancer Res. 52:5223-5228.

18. Trentin, L., et al. 1990. Mechanisms accounting for the defective natural killer activity in patients with hairy cell leukemia. Blood. 75:1525-1530.

19. Cerutti, A., et al. 1996. The CD5/CD72 receptor system is coexpressed with several functionally relevant counterstructures on human B cells and delivers a critical signaling activity. J. Immunol. 157:1854-1862.

20. Trentin, L., et al. 1997. B lymphocytes from patients with chronic lymphoproliferative disorders are equipped with different costimulatory molecules. Cancer Res. 57:4940-4947.

21. Trentin, L., et al. 1994. Expression and regulation of tumor necrosis factor, interleukin-2, and hematopoietic growth factor receptors in B-cell chronic lymphocytic leukemia. Blood. 84:4249-4256.

22. Grynkiewicz, G., Poenie, M., and Tsien, R.Y. 1985. A new generation of $\mathrm{Ca}^{2+}$ indicators with greatly improved fluorescence properties. J. Biol. Chem. 260:3440-3450.

23. Di Virgilio, F., Steinberg, T.H., Swanson, J.A., and Silverstein, S.C. 1988.
Fura- 2 secretion and sequestration in macrophages. A blocker of organic anion transport reveals that these processes occur via a membrane transport system for organic anions. J. Immunol. 140:915-920.

24. Weng, Y., et al. 1998. Binding and functional properties of recombinant and endogenous CXCR3 chemokine receptors. J. Leukoc. Biol. 273:18288-18291.

25. D'Apuzzo, M., et al. 1997. The chemokine SDF-1, stromal cell-derived factor 1, attracts early stage B cell precursors via the chemokine receptor CXCR4. Eur. J. Immunol. 27:1788-1793.

26. Farace, F., et al. 1994. T cell repertoire in patients with B chronic lymphocytic leukemia. Evidence for multiple in vivo T cell clonal expansions. J. Immunol. 153:3281-3290.

27. Kluin-Nelemans, J.C., et al. 1996. Persistent clonal excess and skewed Tcell repertoire in T cells from patients with hairy cell leukemia. Blood. 87:3795-3802.

28. Rabin, R.L., et al. 1999. Chemokine receptor responses on T cells are achieved through regulation of both receptor expression and signaling. J. Immunol. 162:3840-3850.

29. Murgia, M., et al. 1994. Cytosolic free calcium concentration in the mitogenic stimulation of T lymphocytes by anti-CD3 monoclonal antibodies. Cell Calcium. 16:167-180.

30. Semenzato, G. 1998. Chemotactic cytokines: from the molecular level to the clinical use. Sarcoidosis Vasc. Diffuse Lung Dis. 15:131-133. 